\section{Japan promotes nuclear power}

\section{Tokyo}

DESPITE a major accident earlier this year at the Mihama nuclear power plant that shook public confidence in nuclear power, the Japanese government intends to press ahead with ambitious plans to expand the use of atomic energy, according to the latest annual report on atomic energy released by the Science and Technology Agency (STA) last week. But growing public opposition to the siting of nuclear plants may thwart the government's plans.

The annual report devotes several pages to the Mihama accident in February, which was the first time an emergency cooling system had come into play in Japan to prevent meltdown of a reactor core $(\mathrm{Na}$ ture 349, 557; February 1991). The report argues that the accident, caused by a rupture in the primary cooling system of the reactor, demonstrated that the "engineering safety" of Japanese nuclear power plants "has been confirmed" because the emergency cooling system functioned properly and there were no harmful effects on the environment.

But the report admits that Mihama has aroused feelings of "anxiety" in the general public. And it calls for promoting a "correct understanding" of the need for nuclear power with lectures, telephone answering services, personal computer communication links, visits to plants and the loaning of simple radiation-measuring equipment to the public. The report also says it is important to give actual examples that show how the construction of nuclear power plants contributes to the development of local communities in the vicinity.

The government has a powerful array of subsidies to offer local governments that accept nuclear power plants (see below). But, despite the vast sums of money local communities can receive, very few are now prepared to accept new plants.

The government's plans call for a doubling in the number of nuclear plants to about 80 by the year 2010 to supply 43 per cent of Japan's electricity needs, compared with the present 40 commercial plants that provide about 26 per cent. But of the approximately 40 new 1-megawatt plants needed to meet the government's target, sites have only been found for 12 and most of these are on the grounds of existing nuclear power plants.

Hideaki Tsuzuku, deputy director of the Office of Atomic Energy Policy Research of STA's Atomic Energy Bureau, admits that the government is "under very trying circumstances in trying to obtain in a very credible manner the targets we have set."

Another problem facing the government is the need to introduce the use of highly toxic and dangerous plutonium to Japan's ordinary nuclear power plants over the next decade. Starting in the second half of next year, Japan will import plutonium from France and the United Kingdom that has been reprocessed from spent Japanese nuclear fuel. Japan is under contract to ship about 30 tons of plutonium from

\title{
The pursuasive power of yen
}

Tokyo

THE Japanese government provides lavish subsidies to local communities that accept nuclear power. Even so, finding new sites for nuclear plants is proving increasingly difficult (see above).

Under a law introduced in 1974 after the Middle East oil crisis, local governments that accept electric power plants or nuclear power-related facilities are entitled to a variety of central government subsidies. The subsidies are particularly large for nuclear power plants.

This fiscal year, $¥ 178,700$ million $(\$ 1,400$ million) has been set aside under the law, 9.5 per cent more than last year. The funds come from a tax on electricity use that currently runs at $¥ 445$ per thousand kilowatt-hours. The funds are not subject to the strict ceilirigs of other government budgets, and use of electricity is growing rapidly in Japan.

About half of the funds ( $¥ 87,100$ million) are in the form of subsidies to build new local community facilities. The size of subsidy depends on the kilowatt output and type of power plant. Nuclear power plants get by far the largest subsidies.

The other half goes mainly to subsidies for local industrial development ( $¥ 16,200$ million), promotion of public acceptance of electric (in particular, nuclear) power plants ( $¥ 12,900$ million), and subsidies and subcontracts for testing and checking the safety and reliability of nuclear power plants ( $¥ 36,200$ million).

In the case of the little village of Rokkasho in northern Japan, which has accepted three commercial plants for the reprocessing and enrichment of nuclear fuel and storage of nuclear waste, the government will provide $¥ 18,000$ million ( $\$ 140$ million) in subsidies over ten years. The money, which amounts to more than $\$ 10,000$ for every man, woman and child in the village, will be used for 96 village projects, including radar facilities for fishermen, a fertilizer plant for farmers, a sports amenity centre and a ski resort.
Europe by 2010 , Tsuzuku says.

Originally the government planned to use the plutonium in fast breeder reactors. But, with development of commercial fast breeders delayed by decades, most of the plutonium will have to be used in ordinary reactors by mixing it with uranium fuel because it would be against the nuclear non-proliferation treaty, to which Japan is a party, to store vast quantities of weapons-grade plutonium.

However, it is very much in doubt whether local communities will accept the use of plutonium in nearby plants. At the very least, the government will have to come up with even larger subsidies to promote acceptance. David Swinbanks

\section{X-RAY ASTRONOMY}

\section{Ginga to fall soon}

Tokyo

JAPAN's X-ray astronomy satellite Ginga is expected to burn up in the Earth's upper atmosphere sometime this week after producing a wealth of data for the world's astrophysicists during the past five years.

Ginga was launched by Japan's Institute of Space and Astronautical Science (ISAS) in February 1987 and carried Xray detectors developed in collaboration with Leicester University in England and a US-built gamma-ray burst detector ( $\mathrm{Na}$ ture $325, \mathbf{5 6 7} ; \mathbf{1 9 8 7}$ ). It cost only about $\$ 50$ million to build and launch - a fraction of the cost of US and European space satellites.

Within months of launch the satellite made scientific headlines by detecting $X$ rays from the supernova in the Large Magellanic Cloud. This was followed by a string of other achievements, including discovery of two very bright galactic transients that are strong candidates as black holes; detection of cyclotron absorption lines in gamma-ray burst spectra thought to come from a highly magnetized neutron star; discovery of five new X-ray pulsars; detailed studies of the quasi-periodic oscillations of a neutron star; detection of dramatic rises in luminosity of quasars; and sensitive studies of cosmic X-ray background.

Approximately 100 scientists have made use of Ginga. The satellite has produced 17 $\mathrm{PhD}$ theses, including three each from the United States and United Kingdom, and several more are in preparation.

At the time of Nature going to press, ISAS scientists predicted that Ginga is most likely to plunge into the atmosphere on Friday 1 November, but its demise could come at any time between 31 October and 3 November. ISAS will continue to collect data right up to the last minute. But the satellite's bumpy ride through the upper atmosphere is making it difficult to point the satellite's detectors in a fixed direction during its final hours.

David Swinbanks 